NEBOJŠA S. MARINKOVIĆ ${ }^{*}$, KOTARO SASAKI RADOSLAV R. ADŽIĆ ${ }^{2}$

${ }^{1}$ Columbia University, Department of Chemical Engineering, New York, U.S.A., ${ }^{2}$ Chemistry Department, Brookhaven National Laboratory, Upton, U.S.A.
Review paper

ISSN 0351-9465, E-ISSN 2466-2585

UDC:620.186:541.128(n)

doi:10.5937/ZasMat1601101M

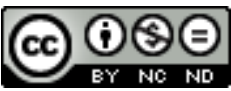

Zastita Materijala 57 (1)

$101-109(2016)$

\title{
Nanoparticle size evaluation of catalysts by EXAFS: Advantages and limitations
}

\begin{abstract}
In this article we determine particle size of nanocatalysts using the first-shell fitting results of Extended X-ray Absorption Fine Structure (EXAFS) measurements. The EXAFS technique measures the average coordination number of nanoparticles in the path of $X$-ray beam. Since nanoparticles can be found in variety of cluster structures with varying coordination number of surface atoms, the discussion is limited to the structures of face centered cubic (fcc) lattice in which most metals of interest for catalysis crystalize. Two nanoparticle structures, namely cuboctahedron and icosahedron, were analyzed and their calculated average coordination numbers compared to those determined by EXAFS. It was found that the particle size determined using EXAFS corresponds best to the diameter of the sphere that has the same volume as the nanoparticle. This volume-corrected sphere was calculated for a number of platinum group metals. It is further shown that the model for particle size evaluation can be extended to bimetallic and trimetallic nanoparticles. Advantages and limitations of the technique in assessing the particle size are discussed.
\end{abstract}

Keywords: Extended X-ray Absorption Fine Structure, EXAFS, nanoparticles, particle size, cuboctahedron, icosahedrons.

\section{INTRODUCTION}

Metallic nanoparticles have unique physical and chemical properties attractive for use in various research areas, in particular as the active catalysts when placed on suitable carbon, metal or oxide supports [1]. Supported metal catalysts, especially those of the platinum group are widely used in fuel cells, as well as catalysts for a variety of chemical synthesis and environmental remediation $[2,3]$. Their small size makes them difficult to characterize by ordinary techniques like chemisorption[4,5], X-ray diffraction (XRD) or transmission electron microscopy (TEM) [6]. The latter technique became increasingly popular in elucidating the statistical spread in nanoparticle sizes; however the instability of the nanoparticles in the electron beam is often a problem. EXAFS is considered the method of choice for the nanoparticle characterization because of its unique ability

\footnotetext{
*Corresponding author: Nebojša Marinković

E-mail: marinkov@bnl.gov

Paper received: 23. 11. 2015.

Paper accepted: 31. 12. 2015.

Paper is available on the website: www.idk.org.rs/casopis
}

to: (a) elucidate the distances between atoms, (b) reveal the average particle size or particles smaller than ca. $2 \mathrm{~nm}$ (unlike XRD), (c) provide details on the shape of the nanoparticle (unlike chemisorption or XRD), as well as because (d) it can be used under in-situ or in operando conditions (unlike TEM). Since it is element-specific, it can reveal the atoms in the nanoparticle and their mole fractions [7], similar to inductively coupled plasma (ICP). In addition, for bimetallic clusters it can reveal the inner structure of nanoparticle and discover whether the nanoparticle represents homogeneous solution, heterogeneous core-shell structure or aggregate of particles constructed of atoms of one type only[8].

Mathematical expression for EXAFS oscillations depends on the X-ray energy, distance between the $\mathrm{X}$-ray absorber to the neighbor, coordination number of identical neighboring atoms, as well as a number of other parameters that are not a priori known but determined through the least-square fitting of the experimental spectrum to a theoretical model. There is no direct relationship to the size of the sample, so for nanoparticles EXAFS determines the size through the coordination number of atoms in them. However, unlike TEM that can identify individual 
particles and their sizes, EXAFS measures an average coordination number (ACN) of all absorbing atoms in the X-ray path [9]. As the crosssection of ordinary EXAFS technique is typically of the order of $1-5 \mathrm{~mm}^{2}$, the technique reveals the ACN of all nanoparticles irrespective of their shapes and sizes. However, as it will be shown below, ACN depends on both the size and the shape of nanoparticles.

\section{RESULTS AND DISCUSSION}

The average size of the nanoparticles obtained by EXAFS determination of ACN has been a topic of numerous discussions and particle size dimensions have been compared to those determined using chemisorption, XRD and TEM as well as to other synchrotron techniques $[4,5,6,10]$. Mathematical expressions of $\mathrm{ACN}$ are evaluated for monometallic nanoparticles that crystallize in face-centered cubic (fcc) lattice structure because nanoparticles of interest for catalysis possess fcc structure (Pt, Rh, Ir, Au and others). An atom in the bulk of the fcc structure has twelve nearest neighbors, i.e. the coordination number (CN) equals to 12; a surface atom has lower CN because a certain number of its neighboring atoms are missing, and its $\mathrm{CN}$ depends of the arrangement of remaining atoms in its vicinity. Two structures of fcc nanoparticles made of complete concentric shells are cuboctahedron $(\mathrm{CH})$ and icosahedrons $(\mathrm{IH})$, Figure 1. The two shapes differ in their surface atomic arrangement. While $\mathrm{IH}$ is constructed of twenty equilateral triangles with (111) surfaces that have $\mathrm{CN}$ of $9, \mathrm{CH}$ is composed of eight (111) triangles and six (100) surfaces that have $\mathrm{CN}$ of 8 ; in addition, vertices and sides of $\mathrm{IH}$ both have higher coordination number than $\mathrm{CH}(6$ and 8 for $\mathrm{IH}$, vs. 5 and 7 for $\mathrm{CH}$ ) so that icosahedron has somewhat larger ACN than cuboctahedron [11]. This difference in ACN of the two nanoparticles is more pronounced for smaller nanoparticles having large surface/volume ratios. For a nanoparticle made up of two concentric shells in which the first shell consists of one atom with $\mathrm{CN}=12$ and the second shell is made of 12 atoms having smaller $\mathrm{CN}$, the $\mathrm{ACN}$ for $\mathrm{IH}$ is about
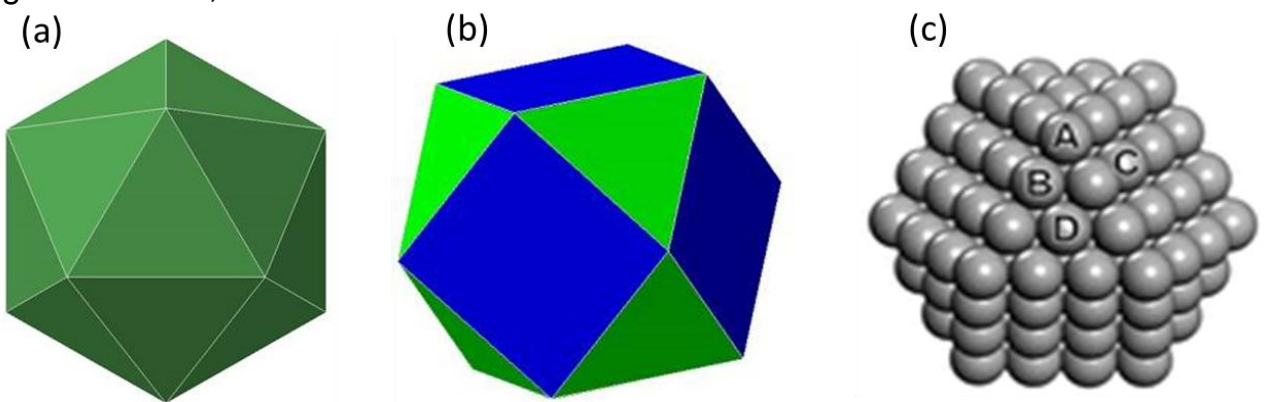

Figure 1 - Shapes of: (a) icosahedron, constructed of 20 triangular surfaces with (111) surface atom arrangement and (b) cuboctahedron, composed of eight triangular faces with (111) orientation and six square faces of (100) surface atom arrangement. Atomic arrangement of cuboctahedron (c), shows atoms

in vertices $(A)$, sides $(B)$ and in surfaces of (100) and (111) orientations $(C$ and $D)$.
$17 \%$ larger than that of $\mathrm{CH}$ due to the different packing of surface atoms. As the number of concentric shells increases, the contribution of the surface atoms' coordination number to ACN diminishes and the difference between ACN for the two shapes becomes smaller. Given the large (+ $10 \%$ ) uncertainty of the EXAFS in determining ACN due to the high correlation of coordination number with other parameters of EXAFS equation that transpires in the estimate of the particle size [12], the difference between ACN for the two nanoparticle shapes quickly becomes indistinguishable by the EXAFS technique.

A number of attempts have been made to elucidate the size of nanoparticles of fcc metals by ACN. In some, the nanoparticle size is approximated to the cluster nuclearity, but without the account to cluster geometry $[13,14]$. Precise mathematical expressions for $A C N$ and the contribution of surface atoms for $\mathrm{CH}$ and $\mathrm{IH}$ made up of complete shells as a function of the total number of atoms were first derived by Benfield [11]; Montejano-Carrizales et al., extended this expression to nanoclusters of other crystal structures [15]. However, no correlation of ACNs to the particle size was derived in either work. Jentys calculated ACNs of spherical clusters according to the above formulae for cuboctahedral particles of fcc lattice with unit cell size of $0.3923 \mathrm{~nm} \mathrm{(Pt}$ lattice) and gave the dimensions of the nanoparticles; however, no reference to the method used to derive the particle size was given [16]. Here we shall attempt to correlate the above works in order to estimate the particle size on the basis of ACN and cluster size geometry.

\subsection{Diameters of icosahedron and cuboctahedron based on geometry}

Let us consider particle sizes of different geometries. For a sphere, the particle size equals to its diameter. However, particle clusters made up of (spherical) atoms assume non-spherical shapes. The two fcc nanoparticles with complete shells (i.e. no missing atoms) are shown in Figure 1, together with packing of atoms in cuboctahedron. 
As seen in the picture, both structures possess sides of equilateral triangles. If each side is made up of row of adjacent atoms, the length of the side equals to $m d$, where $m$ is the number of atoms and $d$ is the diameter of an atom. As both $\mathrm{CH}$ and $\mathrm{IH}$ are regular particles that can be inscribed into a sphere that passes through all vertices, in the first approximation the particle size of $\mathrm{IH}$ and $\mathrm{CH}$ equals to the diameter of enclosing sphere.

The radius of enclosing sphere for cuboctahedron equals to the length of its side [17]. Thus, the diameter of the sphere is:

$$
D_{C H}=2 m d
$$

For icosahedron, the diameter of enclosing sphere is approximately $5 \%$ smaller [17]:

$$
D_{I H}=\sqrt{\frac{5+\sqrt{5}}{2}} m d \approx 1.90 m d
$$

However, the diameters of the enclosing spheres have both larger volume and larger surface area than those of nanoparticles. Perhaps a more accurate way to express the size of a nanoparticle would be to assume that it equals to the diameter of an imaginary sphere that has a certain quantity (e.g. volume, surface area, or mass) equal to that of the nanoparticle [18]. The volume- and surface- corrected particle diameters can be derived from the expressions for volume and surface of the two nanoparticle shapes as follows.

Volume-corrected nanoparticle dimension can be obtained by equalizing the volume of cuboctahedron $\mathrm{V}_{\mathrm{CH}}$ of a side $a=m d$ to the volume of the effective sphere $V_{\mathrm{Sph}}$ with the radius $r_{\text {eff }}^{v}$ as:

$$
V_{C H}=\frac{5}{3} \sqrt{2}(m d)^{3}=V_{S p h}=\frac{4}{3} \pi r_{\text {eff }}^{v^{3}} .
$$

Expressing the equation (3) for the effective radius, one obtains the diameter of the effective sphere corresponding to the volume-corrected particle size for cuboctahedron:

$$
D_{\text {eff }}^{v}=2 r_{\text {eff }}^{v} \approx 1.65 \mathrm{md}
$$

Comparing this diameter to that of the enclosed sphere, one finds that the volume-corrected diameter is about $21 \%$ smaller.

Surface area of the cuboctahedron equals to the sum of surface area of eight equilateral triangles and six squares, all having the side length of $m d$. Equalizing this area to the surface area of a sphere, one finds the effective radius of a surfacecorrected sphere for cuboctahedron, $r_{\text {eff }}^{s}$ :

$A_{C H}=8 \frac{\sqrt{3}}{4}(m d)^{2}+6(m d)^{2}=A_{S p h}=4 \pi r_{\text {eff }}^{s^{2}}$,

so the surface-corrected particle size for cuboctahedron is:

$$
D_{\text {eff }}^{s} \approx 1.74 \mathrm{md}
$$

This surface-corrected particle size is about $15 \%$ smaller than that of the enclosed sphere of cuboctahedron.

Effective radii for icosahedron are found in the similar way. It can be shown that the volumecorrected and surface-corrected diameters for the icosahedron are about 18 and $15 \%$ smaller, respectively, than that of the enclosed sphere.

Table 1 - Expressions for volume and surface of a sphere with a radius $r$, cuboctahedron and icosahedron with the side $a=m d$ where $m$ is the number of atoms with the diameter $d$ in the side (top part), and nanoparticle dimensions calculated as the diameter of enclosed sphere that passes through vertices of nanoparticle, the diameter of a sphere that has the same volume (Volume-corrected), or the same surface (Surface-corrected) as the nanoparticle.

\begin{tabular}{|c|c|c|c|c|c|}
\hline \multicolumn{2}{|c|}{ Sphere } & \multicolumn{2}{c|}{ Cuboctahedron } & \multicolumn{2}{c|}{ Icosahedron } \\
\hline Volume & Area & Volume & Area & Volume & Area \\
\hline$\frac{4}{3} \pi r^{3}$ & $4 \pi r^{2}$ & $\frac{5}{3} \sqrt{2}(m d)^{3}$ & $(6+2 \sqrt{3})(m d)^{2}$ & $\frac{5(3+\sqrt{5})}{12}(m d)^{3}$ & $5 \sqrt{3}(m d)^{2}$ \\
\hline Diameter of Enclosed Sphere & $2 m d$ & $\sqrt{\frac{5+\sqrt{5}}{2}} m d \approx 1.90 m d$ \\
\hline $\begin{array}{l}\text { Diameter of Volume-corrected } \\
\text { Sphere }\end{array}$ & $2 \sqrt[3]{\frac{5 \sqrt{2}}{4 \pi}} m d \approx 1.65 m d$ & $2 \sqrt[3]{\frac{15+5 \sqrt{5}}{16 \pi}} m d \approx 1.61 m d$ \\
\hline $\begin{array}{l}\text { Diameter of Surface-corrected } \\
\text { Sphere }\end{array}$ & $2 \sqrt{\frac{3+\sqrt{3}}{2 \pi}} m d \approx 1.74 m d$ & $2 \sqrt{\frac{5 \sqrt{3}}{4 \pi}} m d \approx 1.66 m d$ \\
\hline
\end{tabular}

The expressions for volume and surface of a sphere, cuboctahedron and icosahedron, as well as volume- and surface-corrected spheres, obtained by the way described above are 
summarized in Table 1. As seen, the dimensions of cuboctahedron- and icosahedron-shaped nanoparticles range from ca. $1.65 m d$ to $2.0 m d$ for $\mathrm{CH}$, and from ca. $1.61 \mathrm{~m} d$ to $1.90 \mathrm{~m} d$ for $\mathrm{IH}$. But which of the six expressions represents the diameter of the particle measured by EXAFS? We shall try to correlate the particle sizes calculated by these expressions to the published works of other authors, and include our own measurements.

Figure 2 shows the dependence of particle size as a function of the total number of atoms in cuboctahedrons. The data points are calculated as the diameters of enclosed sphere that passes through vertices of cuboctahedron, and diameters of spheres that have either the same volume (volume-corrected) or the same surface area (surface-corrected) as the cuboctahedron of the given number of atoms, packed in fcc lattice with interatomic distance of $0.2775 \mathrm{~nm}$ (Pt-Pt distance). In order to elucidate which of the three calculated hyperbolic curves best describes the particle dimensions given by Jentys [16], its data is also included. It is obvious that the particle sizes given in ref. [16] practically overlap with the volumecorrected diameters. However, due to the inherent uncertainty of EXAFS in determination of coordination numbers, even surface-corrected sphere can be used. On the other hand, the radii calculated on the basis of enclosed sphere are beyond the error bars for any particle size.

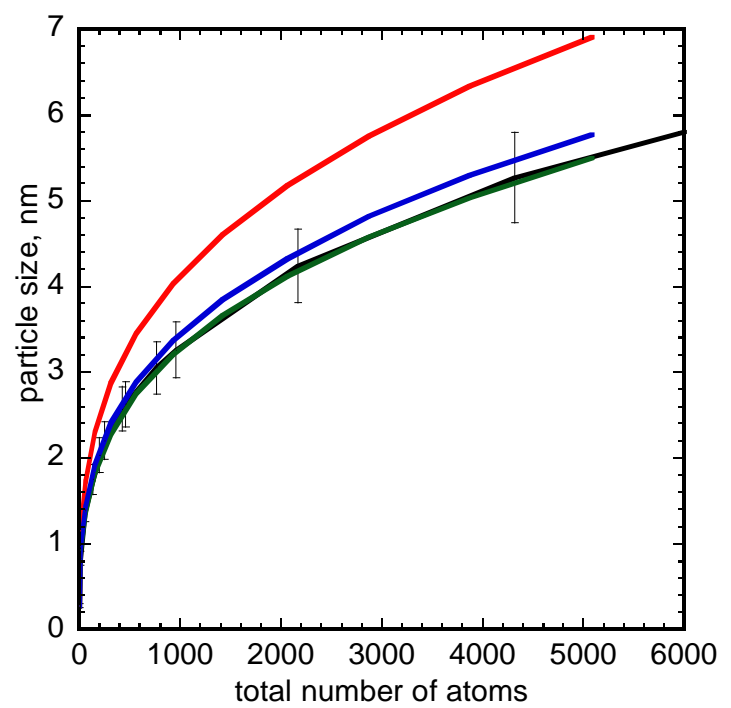

Figure 2 - Comparison of particle sizes calculated based of enclosed sphere that passes through vertices of cuboctahedron (red line), and based on size of the sphere that has the same volume (green)

or the same surface area (blue) as the cubocta-

hedron, as a function of number of atoms packed in fcc lattice with interatomic distance of $0.2775 \mathrm{~nm}$ (Pt-

Pt distance). Data from ref. [16] is given for comparison (black line). Error bars approximate the limit of accuracy in determining the particle size based on the evaluation of ACNs from EXAFS data.
Next, let us compare the particle sizes of different shapes. Figure 3 shows the comparison of volume-corrected sphere diameters for $\mathrm{IH}$ and $\mathrm{CH}$, together with those of enclosed spheres, calculated as a function of total number of atoms. It is interesting to note that the difference in the particle shape does not greatly affect the particle size. The hyperbolic functions for volume-corrected diameters of $\mathrm{IH}$ and $\mathrm{CH}$ as the function of the total number of atoms are close and well within the error bars, calculated by the assumption that the error in determining the particle size by EXAFS is $+10 \%$ of the particle dimension.

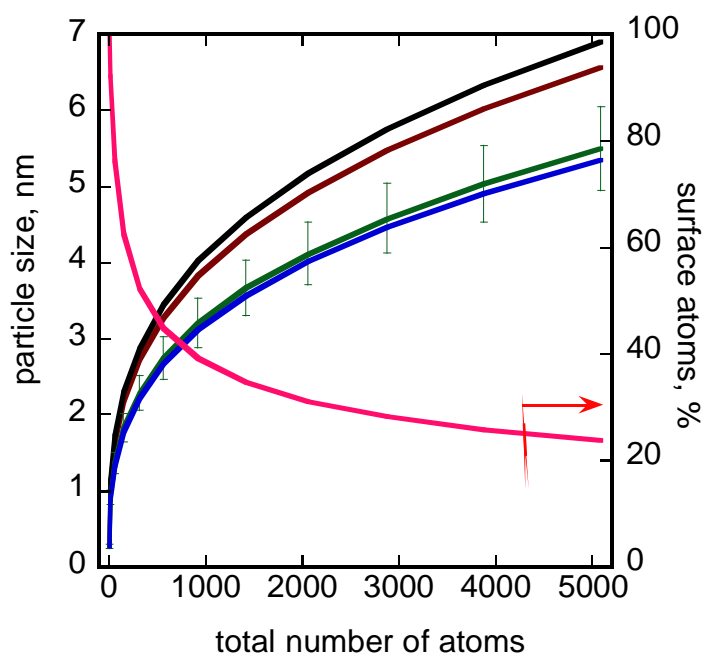

Figure 3 - Comparison of particle sizes calculated based of enclosed sphere that passes through vertices of cuboctahedron and icosahedron (black and brown lines), and based on size of the sphere that has the same volume (Volume-corrected) for the two particles (green and blue lines, respectively). Error bars given for volume-corrected sphere of icosahedron show the typical limit of accuracy in determining the particle size based on EXAFS measurements. Percentage of surface atoms is given for comparison.

Figure 3 also shows the fraction of surface atoms vs. total number of atoms, which is an important aspect in determining ACNs of nanoparticles. Since $\mathrm{IH}$ and $\mathrm{CH}$ are made up of concentric shells of atoms in which the first shell is the single central atom, and a cluster of $m$ completed shells surrounds it, the fraction of surface atoms quickly diminishes from ca. $92 \%$ for the smallest true nanoparticle containing only 13 atoms ( $m=2$, i.e. one atom in the center and 12 atoms surrounding it) to ca. $52 \%$ for a cluster of 309 atoms $(m=5)$ [11]. Consequently, the ACNs for $\mathrm{IH}$ and $\mathrm{CH}$ rise quickly from about 6 for $m=2$ to about 10 for $m=5$ (c.f. Figs. 4 and 5), and then continue to asymptotically rise to the limiting value 
of 12 (the coordination number of an atom in the bulk) with a much smaller slope. Because of the fundamental principles of EXAFS operation, the technique cannot measure individual atoms, so the coordination number of a single atom cannot be determined.

\subsection{Mathematical formulae for $A C N$}

The exact expressions for average coordination number $\bar{N}$ for icosahedrons and cuboctahedrons clusters formed of filled concentric shells as a function of total number of atoms are derived in ref. [11]. The filled concentric shells for both structures are composed of identical number of atoms (socalled 'magic' numbers) with a sequence of 1,13 , 55, 147 etc. ACNs are as follows:

$$
\begin{aligned}
& \bar{N}_{I H}=\frac{6(m-1)\left(20 m^{2}-25 m+12\right)}{(2 m-1)\left(5 m^{2}-5 m+3\right)} \text { and } \\
& \bar{N}_{C H}=\frac{12(m-1)\left(10 m^{2}-14 m+6\right)}{(2 m-1)\left(5 m^{2}-5 m+3\right)}
\end{aligned}
$$

The expressions for total number of atoms and the number of surface atoms are identical for both nanoparticles:

$$
\begin{aligned}
& n(\text { tot })=\left(\frac{1}{3}\right)(2 m-1)\left(5 m^{2}-5 m+3\right) \text { and } \\
& n(\text { surf })=10 m 2-20 m+12
\end{aligned}
$$

It can be seen that the average coordination numbers for the two structures are within $10 \%$ of each other even for the smallest nanoparticle containing 13 atoms (individual atoms are not considered), and becoming comparable for larger particles.

To evaluate the average coordination number $\bar{N}$, Calvin et al. [19] approximated the nanoparticle as a sphere of radius $R$ in which the distance between the absorbing and scattering atom is $r$. For particles composed of only one type of atoms, the interatomic distance $r$ equals to the diameter of the atom $d$, so:

$$
\bar{N} \approx\left(1-\frac{3 d}{4 R}+\frac{d^{3}}{16 R^{3}}\right) N_{\text {bulk }}
$$

where $N_{\text {bulk }}$ is the coordination number of the atom in the bulk. The approach was based on the reduction of the coordination numbers by a factor equal to the fraction of the surface area of the scattering sphere that is contained within the crystallite of radius $R$. Integrating through the crystallite sphere and dividing by its volume yields the reduction in average coordination number relative to the bulk. The authors argued that the approximation should be valid for particles of any lattice structure, including bcc and hcp. Frenkel assumed that the $R$ represents the radius of the enclosing sphere [7]. By comparison of the ACNs calculated for cuboctahedron by the Eq. 9 and the exact expression (Eq. 7), it was found that the approximate expression follows closely the exact one only for atomic clusters composed of more than 100 atoms; however, the approximation produces $A C N$ s that are always larger than exact ones.

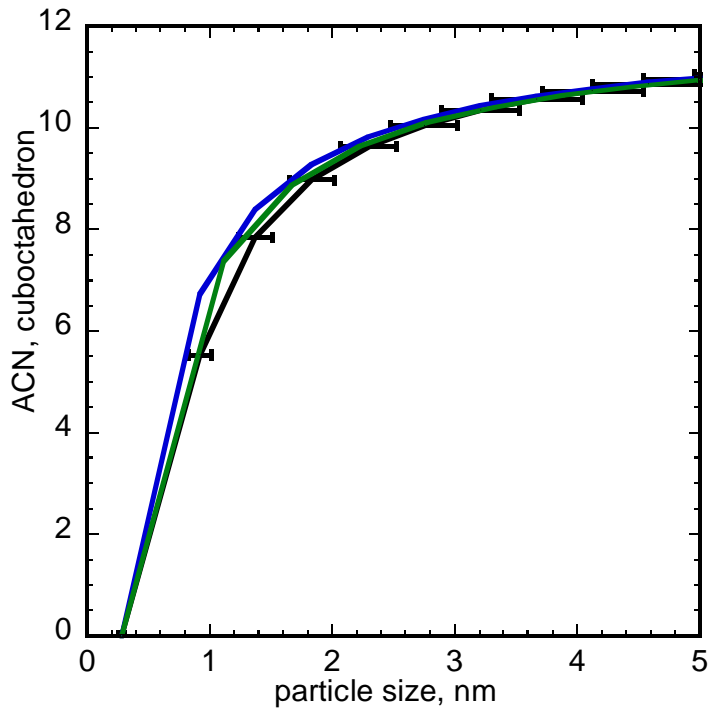

Figure 4 - Comparison of first-shell coordination numbers calculated by the approximate method in ref. [19] assuming enclosed sphere that passes through vertices of cuboctahedron (green line), and based on volume-corrected sphere (blue line) for the atoms packed in fcc lattice with interatomic distance of $0.2775 \mathrm{~nm}$ (Pt-Pt distance). Data from ref. [16] is given for comparison (black line). Error bars are calculated as $A C N+10 \%$.

Indeed, as shown in Figure 4, the approximate method yields ACNs that match closely those calculated on the basis of the volume corrected sphere only for particles larger than ca. $2 \mathrm{~nm}$, but deviate for smaller particles, yielding larger coordination numbers.

\subsection{Monoatomic particles}

Fcc lattice is arguably the most important structure in catalysis, not only because the platinum group of metals crystallize in it, but also because solid solutions of metals often assume the fcc lattice when one metal in the alloy is an fcc metal [11]. Table 2 shows the average coordination numbers for several fcc metals of platinum group of interest in catalysis, calculated by the expressions (Eq. 7) for the icosahedron and cuboctahedron shapes, and particle size calculated as the diameter of the average between volume-corrected spheres of $\mathrm{IH}$ and $\mathrm{CH}$. 
Table 2 - Number of shells, surface and total number of atoms, particle size calculated as the average of volume-corrected spheres for icosahedron and cuboctahedron, and average coordination numbers for icosahedron and cuboctahedron for platinum group of metals, calculated by the formulae given in Ref. [11]

\begin{tabular}{|c|c|c|c|c|c|c|c|c|c|c|}
\hline $\begin{array}{c}\text { Number } \\
\text { of shells }\end{array}$ & $\begin{array}{c}\text { Total } \\
\text { atoms }\end{array}$ & $\begin{array}{c}\text { Surface } \\
\text { atoms }\end{array}$ & $\begin{array}{c}\text { \% of } \\
\text { surface } \\
\text { atoms }\end{array}$ & $\begin{array}{c}\mathrm{Rh} \\
\text { cluster } \\
\text { size } \\
(\mathrm{nm})\end{array}$ & $\begin{array}{c}\mathrm{Ir} \\
\text { cluster } \\
\text { size } \\
(\mathrm{nm})\end{array}$ & $\begin{array}{c}\mathrm{Pd} \\
\text { cluster } \\
\text { size } \\
(\mathrm{nm})\end{array}$ & $\begin{array}{c}\mathrm{Pt} \\
\text { cluster } \\
\text { size } \\
(\mathrm{nm})\end{array}$ & $\begin{array}{c}\mathrm{Au} \\
\text { cluster } \\
\text { size } \\
(\mathrm{nm})\end{array}$ & $\begin{array}{c}\bar{N} \\
\text { (icos) }\end{array}$ & $\begin{array}{c}\bar{N} \\
\text { (cuboct) }\end{array}$ \\
\hline 1 & 1 & 1 & 100 & 0.27 & 0.27 & 0.27 & 0.28 & 0.29 & - & - \\
\hline 2 & 13 & 12 & 92.3 & 0.88 & 0.89 & 0.89 & 0.91 & 0.94 & 6.46 & 5.54 \\
\hline 3 & 55 & 42 & 76.4 & 1.32 & 1.33 & 1.34 & 1.36 & 1.41 & 8.51 & 7.85 \\
\hline 4 & 147 & 92 & 62.6 & 1.76 & 1.77 & 1.78 & 1.81 & 1.88 & 9.47 & 8.98 \\
\hline 5 & 309 & 162 & 52.4 & 2.19 & 2.22 & 2.23 & 2.26 & 2.35 & 10.02 & 9.63 \\
\hline 6 & 561 & 252 & 44.9 & 2.64 & 2.66 & 2.68 & 2.72 & 2.82 & 10.37 & 10.05 \\
\hline 7 & 923 & 362 & 39.2 & 3.07 & 3.10 & 3.13 & 3.17 & 3.29 & 10.62 & 10.35 \\
\hline 8 & 1415 & 492 & 34.8 & 3.51 & 3.55 & 3.58 & 3.62 & 3.76 & 10.8 & 10.57 \\
\hline 9 & 2057 & 642 & 31.2 & 3.95 & 3.99 & 4.02 & 4.07 & 4.22 & 10.94 & 10.73 \\
\hline 10 & 2869 & 812 & 28.3 & 4.39 & 4.43 & 4.47 & 4.53 & 4.70 & 11.05 & 10.87 \\
\hline 11 & 3871 & 1002 & 25.9 & 4.82 & 4.88 & 4.92 & 4.98 & 5.17 & 11.14 & 10.97 \\
\hline 12 & 5083 & 1212 & 23.8 & 5.26 & 5.32 & 5.36 & 5.43 & 5.64 & 11.22 & 11.06 \\
\hline
\end{tabular}

Nanoparticles of other type of metal lattices can assume shapes other than $\mathrm{IH}$ and $\mathrm{CH}$ (e.g. decahedron, dodecahedron, etc.) that have different number of surface atoms and hence different average coordination numbers. The ACNs for various shapes of nanoparticles and for all three types of metallic lattices, fcc, body centered cubic (bcc) and hexagonal close packed (hcp) were calculated recently [20]. Metals crystallizing in close-packed lattice structures with the bulk coordination number of 12 (fcc and hcp) account for about $2 / 3$ of all metals in the periodic system; for them it was shown that the hyperbolic functions of $A C N$ vs. number of total atoms are similar. Furthermore, because of intrinsic uncertainty in determination of ACNs, the number of atoms in fcc or hcp nanoparticle of practically any shape falls within the error bars of experimentally obtained ACN. For instance, ACN of 9 represents a particle of approximately 170 atoms (fcc or hcp) regardless of its shape [20]. For bcc metals, the ACN vs. total number of atoms follows a similar hyperbolic function but is shifted to lower coordination numbers with respect of other two lattices as the bulk coordination number for bcc lattice is 8 .

\subsection{Polyatomic particles}

Interestingly, the discussion above can be extended to the metallic particles composed of two or more metals. For a particle composed of two metals $\mathrm{M} 1$ and $\mathrm{M} 2$ comprising a homogeneous mixture (i.e. solid solution), Figure $5 \mathrm{a}$, it was shown that the total coordination number of one metal, $\Sigma N_{\mathrm{M} 1}=N_{\mathrm{M} 1-\mathrm{M} 2}+N_{\mathrm{M} 1 \mathrm{M} 1}$ must be equal to the total coordination number of the other metal, $\Sigma N_{\mathrm{M} 2}=$
$N_{\text {M2-M1 }}+N_{\text {M2-M2 }}$ [7]. Furthermore, the interatomic distances M1-M1 and M2-M2 in the solid solution differ from the bulk values and can be either larger or smaller depending on the diameter of the other metal $[7,8]$. The particle size of such diatomic cluster can be approximated to a particle composed of one type of atoms only having the diameter that is about half-way between those of metals $M 1$ and M2. For instance, for PtRh solid solution, the Pt-Pt and $\mathrm{Rh}-\mathrm{Rh}$ bond lengths were found to be $0.2743 \mathrm{~nm}$ and $0.2705 \mathrm{~nm}$ respectively, which differ from the bulk values for Pt-Pt and Rh$\mathrm{Rh}(0.2775 \mathrm{~nm}$ and $0.2680 \mathrm{~nm})$, and the particle size was calculated assuming a monoatomic composition with the bond length between the atoms of $0.273 \mathrm{~nm}$, i.e. the average value of $R h-R h$ and Pt-Pt interatomic distances in the bulk [21].
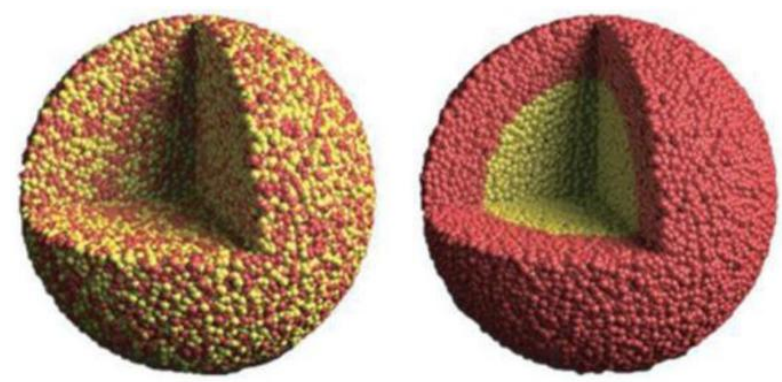

Figure 5 - Homogeneous distribution of atoms in a solid solution (a), and heterogeneous mixture with atoms of one kind located preferentially in the core and atoms of the other in the shell (b).

For heterogeneous mixture of a core-shell structure in which the core is preferentially composed of metal atoms $\mathrm{M} 1$ and the shell of 
metal atoms M2 (see Fig. 5b), the particle size will be similar to a particle composed of M1 atoms only, with the total number of atoms equal to $\mathrm{M} 1+\mathrm{M} 2$; thus, the total coordination number of the core metal M1, $\Sigma N_{\mathrm{M} 1}=N_{\mathrm{M} 1 \mathrm{M} 2}+N_{\mathrm{M} 1-\mathrm{M} 1}$ should be used to estimate the particle size [8]]. This approximation certainly holds well for the particles with the shell of monolayer (one-atom) thickness, but it can also be applied to the particles with thicker shells made of two or three atoms (c.f. Table 3). For a triatomic particle composed of $\mathrm{Pd}_{9} \mathrm{Au}$ alloy core with a $\mathrm{Pt}$ monolayer shell, the core diameter can be approximated as if it was made of one type of atoms only with a diameter of $0.28 \mathrm{~nm}$, i.e. the average value between diameters of $\mathrm{Pd}$ and $\mathrm{Au}$ atoms, corresponding roughly to the interatomic distance of $\mathrm{Pt}$ atoms in the bulk. The coordination number of the core atoms, $\mathrm{CN}(\mathrm{Pd}-\mathrm{Pd}+\mathrm{Pd}-\mathrm{Au})=$ 10. \pm 0.4 , suggests that the core is made of about 7 concentric shells. However, since the alloy core is enclosed in a monolayer shell made of $\mathrm{Pt}$ atoms, the total number of shells equals to 8; furthermore, since the diameter of all atoms in the nanoparticle can be approximated to that of $\mathrm{Pt}$, the nanoparticle size is approximately $3.6 \mathrm{~nm}$ (see Table 2), which agrees well with the average value of $3.8 \mathrm{~nm}$ obtained by TEM [22].

Table 3 summarizes the particle sizes of several nanoparticle catalysts determined by EXAFS and verified by an independent method (TEM or XRD). Since the first-shell fitting produces errors in average coordination numbers that could be as large as \pm 1.0 , the errors in particle size differ dramatically and can be as small as $\pm 0.2 \mathrm{~nm}$ for nanoparticles up to $2 \mathrm{~nm}$, but increase rapidly with

Table 3 - Nanoparticle composition, their structure, average coordination number $(A C N)$, and sizes estimated by XAS and measured by another method. ${ }^{a} A C N$ corresponds to Pd-Au core only.

\begin{tabular}{|l|l|c|c|c|c|}
\hline $\begin{array}{c}\text { Particle } \\
\text { Composition }\end{array}$ & \multicolumn{1}{|c|}{ Particle structure } & ACN & $\begin{array}{c}\text { Particle size by } \\
\text { XAS }(\mathrm{nm})\end{array}$ & $\begin{array}{c}\text { Particle size by other } \\
\text { method }(\mathrm{nm})\end{array}$ & Ref. \\
\hline $\mathrm{Rh}$ & Monoatomic & $7.7 \pm 0.4$ & $1.3 \pm 0.2$ & $1.3(\mathrm{TEM})$ & {$[25]$} \\
\hline $\mathrm{Pt}$ & Monoatomic & $9.3 \pm 0.5$ & $2.1 \pm 0.7$ & $2.6(\mathrm{XRD})$ & {$[26,27]$} \\
\hline $\mathrm{Pt}-\mathrm{Rh}$ & Solid solution & $10 \pm 0.8$ & $2.4 \pm 0.3$ & $2.3(\mathrm{TEM})$ & {$[21]$} \\
\hline $\mathrm{Pt}-\mathrm{Rh}$ & Solid solution & $9.1 \pm 0.8$ & $2.0 \pm 0.5$ & $2.1(\mathrm{TEM})$ & {$[28]$} \\
\hline $\mathrm{Ni}-\mathrm{Ir}$ & Core-bilayer shell & $11 \pm 0.7$ & $4.0 \pm 1.0$ & $4.7(\mathrm{XRD})$ & {$[29]$} \\
\hline $\mathrm{Pd}-\mathrm{Pt}$ & Core-monolayer shell & $11 \pm 0.7$ & $4.5 \pm 1.0$ & $4.2(\mathrm{TEM})$ & {$[30]$} \\
\hline $\mathrm{Pd} \mathrm{du}_{9} \mathrm{Au}-\mathrm{Pt}$ & PdAu core-Pt shell & $10 \pm 0.7^{\mathrm{a}}$ & $3.6 \pm 0.6$ & $3.8(\mathrm{TEM})$ & {$[22]$} \\
\hline
\end{tabular}

\section{CONCLUSION}

EXAFS is a technique of choice for characterization of nanoparticles because of its ability to replace several techniques like chemisorption, XRD, TEM, and ICP. The size of nanoparticles the EXAFS technique measures larger particles as ACN approaches the bulk limit. For instance, ACN of $10.5 \pm 1.0$ corresponds to a particle size of anywhere between 2 and $5 \mathrm{~nm}$. Hence, the first-shell fitting gives accurate particle sizes only for nanoparticles not larger than ca. 3 $\mathrm{nm}$. Because of relatively small spread of interatomic distances of platinum group fcc metals, the nanoparticle clusters of the smallest and the largest atoms in Table 2 ( $R h$ and $\mathrm{Au}$ ) are not very different in sizes. Even for the cluster constructed of twelve concentric shells the particle sizes between $\mathrm{Rh}$ and $\mathrm{Au}$ differ by less than $0.4 \mathrm{~nm}$, which is indistinguishable by EXAFS given the large uncertainty in determination of average coordination numbers[12]. Thus, even though EXAFS is element-specific technique with the ability to distinguish different atoms and determine interatomic distances with great accuracy, its ability to determine the particle size is limited to relatively small nanoparticles. Its average particle size value should be taken only as a first approximation when the ACN together with its uncertainty approaches the limiting value of 12 , i.e. for particles larger than 3 or $4 \mathrm{~nm}$, depending on the range of experimental error. However, other laboratory techniques for particle size evaluation (XRD and TEM) are limited to atomic clusters larger than ca. $2 \mathrm{~nm}$ because of the need for a long-range atomic order (XRD), or their resolution is of the order of $1 \mathrm{~nm}$ (TEM) $[23,24]$. Thus the EXAFS technique should be considered more as complementary technique to XRD and TEM in particle size evaluation, rather than mutually excluding, because of the limited capabilities of the techniques at different scales. through determination of average coordination numbers. As the typical $x$-ray beam size is orders of magnitude larger than that of nanoparticles, it gives the average size of all the particles in its path. Because of the inherent uncertainty of coordination numbers due to their correlation with other parameters of EXAFS equation, the average 
coordination number obtained by first shell fitting produces relatively accurate dimension of nanoparticles up to about $3 \mathrm{~nm}$. For larger particles, the diameter of the particle obtained by EXAFS technique should be used as a first approximation only, and thus should be verified by an independent technique.

\section{Acknowledgments}

This research was performed at Brookhaven National Laboratory under contract DE-SC0012704 with the US Department of Energy, Office of Basic Energy Science, Material Science and Engineering Division, Division of Chemical Sciences, Geosciences and Biosciences Division. Beamlines X18A, $X 18 B$, and X19A at the NSLS, as well as BL 2-2 at the SSRL were supported in part by the Synchrotron Catalysis Consortium, U.S. Department of Energy Grant No DE-SC0012335.

\section{REFERENCES}

[1] A.T.Bell (2003) The Impact of nanoscience on heterogeneous catalysis, Science, 299, 1688-1691.

[2] J.W.Geus, J.A.R. van Veen (1990) Preparation of supported catalysts, Stud. Surf. Sci. Catal., 79, 335360.

W.Yu, M.D.Porosoff, J.G.Chen (2012) Review of Ptbased bimetallic Catalysts: From model surfaces to supported catalysts, Chem. Rev., 112(11), 57805817.

[3] B.J. Kip, F.B.M. Duivenvoorden, D.C. Konningsberger, R. Prins (1987) Determintaion of metal particle size of highly dispersed $\mathrm{Rh}$, Ir and $\mathrm{Pt}$ by hydrogen chemisorption and EXAFS, J. Catal., 105(1), 26-38.

[4] S.H.Hakim, C.Sener, A.C.Alba-Rubio, T.M.Gostanian, B.J.O'Neill, F.H.Ribeiro, J.T.Miller, J.A.Dumesic (2015) Synthesis of supported bimetallic nanoparticles with controlled size and composition distributions for active site elucidation, J. Catal., 328, 75-90.

[5] P.Canton, P.F.Fazzini, C.Meneghini, A.Benedetti G.Pozzi (2008) Nanoscale characterization of metal nanoclusters by means of X-Ray Diffraction (XRD) and Transmission Electron Microscopy (TEM) techniques, in B. Corain, G. Schmid and N. Toshima (Eds.) Metal nanoclusters in catalysis and materials science: The issue of size control, Elsevier, New York, 129-147.

[6] A.Frenkel (2007) Solving the 3D structure of metal nanoparticles, Z. Kristallogr., 222(11), 605-611.

[7] K.Sasaki, N.Marinkovic (2016) X-ray absorption spectroscopic characterization of nanomaterial catalysts in electrochemistry and fuel cells, in C.S.S.R. Kumar (Ed.), X-ray and neutron techniques for nanomaterials characterization, Chapter 6, Springer-Verlag, Berlin..

[8] S. Calvin (2013) EXAFS for everyone, CRC Press Taylor and Francis Group, Boca Raton, FL.
[9] D.C.Bazin, D.A.Sayers, J.J.Rehr (1997) Comparison between X-ray Absorption Spectroscopy, Anomalous Wide Angle X-ray Scattering, Anomalous Small Angle X-ray Scattering, and Diffraction Anomalous Fine Structure Techniques Applied to Nanometer-Scale Metallic Clusters, J. Phys. Chem. B, 101(51), 11040-11050.

[10] R.E.Benfield (1992) Mean coordination numbers and the non-metal-metal transition in clusters, J. Chem. Soc. Faraday Trans., 88(8), 1107-1110.

[11] M. Vaarkamp (1998) Obtaining reliable structural parameters from EXAFS, Catal. Today, 39(4), 271 279.

[12] H.Muller, C.Opitz, L.Skala (1989) The highly dispersed metal state - physical and chemical properties, J. Mol. Catal., 54(3), 389-405.

[13] R.N.Bhatt, T.M.Rice (1979) Theory of optical absorption in expanded fluid mercury. Phys.Rev. B, 20(2), 466-475.

[14] J.M. Montejano-Carrixales, F. Aguilera-Granjam , J.L. Moran-Lopez (1997) Direct enumeration of the geometrical characteristics of clusters, NanoStructured Mater., 8(3), 269-287.

[15] A. Jentys (1999) Estimation of mean size and shape of small metal particles by EXAFS, Phys. Chem. Chem. Phys., 1(17), 4059-4063.

[16] K.J.M. MacLean (2007) A geometric analysis of Platonic solids and other regular polyhedra. Cuboctahedron - (http://www.kjmaclean.com/ Geometry/Cubeoctahedron.html)

[17] Icosahedron - (http://www.kjmaclean.com/Geometry /lcosahedron.html)

[18] Particle size: https://en.wikipedia.org/wiki/ Particle_size

[19] S. Calvin, M.M. Miller, R.Goswami, S.F.Cheng, S.P.Mulvaney, L.J.Whitman, V.G.Harris (2003) Definition of crystalline size in magnetic nanocomposite using extended X-ray absorption fine structure, J. Appl. Phys., 94(1), 778-783.

[20] A.M.Beale, B.M.Weckhuysen (2010) EXAFS as a tool to interrogate the size and shape of mono and bimetallic catalyst nanoparticles, Phys. Chem. Chem. Phys., 12(21), 5562-5574.

[21] A. Kowal, M. Li, M.Shao. K.Sasaki, M. B.Vukmirovic, J.Zhang, N.S.Marinkovic, P.Liu, A.I. Frenkel, R.R.Adzic (2009) Ternary $\mathrm{Pt} / \mathrm{Rh} / \mathrm{SnO}_{2}$ electrocatalsysts for oxidizing ethanol to $\mathrm{CO}_{2}$, Nature Materials, 8, 325-330.

[22] K.Sasaki, H.Naohara, Y.M.Choi, Y.Cai, W.F.Chen, P. Liu, R.R.Adzic (2012) Highly stable Pt monolayer on PdAu nanoparticle electrocatalysts for the oxygen reduction reaction, Nature Commun. 3, 2115.

[23] A.Frenkel, Q.Wang, N.Marinkovic, J.Chen, L.Barrio, R.Si, A. López Cámara, M.Estrella, J. Rodriguez, J.Hanson (2011) Combining X-Ray absorption and X-Ray diffraction techniques for in situ studies of chemical transformations in heterogeneous catalysis: Advantages and limitations, J. Phys. Chem. C, 115(36), 17884-17890. 
[24] S.Zhao, Y.Li, E.Stavitski, R.Taperro, S.Crowley, M.J. Castaldi, D.N.Zakharov, R.G.Nuzzo, A.I. Frenkel, E.A.Stach (2015) Operando characterization of catalysts through use of a potable microreactor, Chem Cat Chem, 7(22), 3683-3691.

[25] J.C.Matsubu, S.Zhang, L.DeRita, N.S.Marinkovic, J.G.Chen, G.W.Graham, X.Pan, P.Christopher, Adsorbate-Mediated Strong Metal-Support Interactions in Oxide Supported Rh Catalysts, Nature Chemistry, submitted.

[26] K.Sasaki, N.Marinkovic, H.S.Isaacs, R.R.Adzic (2016) Synchrotron-based in situ characterization of carbon-supported platinum and platinum monolayer electroctalysts, ACS Catalysis 6(1), 69.

[27] K.Sasaki, N.Marinkovic, H.S.Isaacs, R.R. Adzic (2016), in preparation.
[28] M.Li, N.Marinkovic, K.Sasaki (2012) In situ characterization of ternary $\mathrm{Pt}-\mathrm{Rh}-\mathrm{SnO}_{2} / \mathrm{C}$ catalysts for ethanol electrooxidation, Electrocatalysis, 3(3), 376-385.

[29] K.Sasaki, K.A.Kuttiyiel, L.Bario, D.Su, A.I.Frenkel, N.Marinkovic, D.Mahajan, R.R.Adzic (2011) Carbon-Supported IrNi Core_Shell Nanoparticles: Synthesis, Characterization, and Catalytic Activity, J.Phys. Chem C 115, 9894-9902.

[30] K.Sasaki, J.X.Wang, H.Naohara, N.Marinkovic, K.More, R.R.Adzic (2010) Recent advances in platinum monolayer electrocatalysts for oxygen reduction reaction: Scale-up synthesis, structure and activity of Pt shells and Pd cores, Electrochim. Acta, 55(8), 2645-2652.

\section{IZVOD}

\section{PROCENA VELIČINA NANOČESTICA KATALIZATORA ZA EXAFS: PREDNOSTI I OGRANIČENJA}

U ovom radu opisujemo određivanje veličine nano-čestica katalizatora pomoću analize rezultata dobijenih merenjem proširene apsorpcije $X$ zraka fine strukture (EXAFS). EXAFS tehnika daje prosečan koordinacioni broj nanočestica na putu x-zraka. Kako se nanočestice mogu naći u različitim strukturama klastera u kojim koordinacioni broj površinskih atoma varira, diskusija je ograničena na strukture površinski centrirane kubne (fcc) rešetke u kojoj kristališe većina metala od interesa za katalizu. Analizirane su dve nanočestične strukture, tj. kuboktahedron $i$ ikosahedron, i njihovi izračunati prosečni koordinacioni brojevi su upoređeni sa brojevma dobijenim EXAFS tehnikom. Nađeno je da veličina čestica koju EXAFS određuje najbolje odgovara prečniku sfere koji ima istu zapreminu kao ta nanočestica. Ova zapreminski korigovana sfera je izračunata za jedan broj metala platinske grupe. Takođe je pokazano da je ovaj model moguće primeniti i za bimetalne $i$ trimetalne nanočestice. Analizirane su prednosti $i$ ograničenja ove tehnike u određivanju veličine čestica.

Ključne reči: Proširena apsorpcija X-zraka fine strukture, EXAFS, nanočestice, veličina čestice, kuboktahedron, ikozahedron.

\section{Pregledni rad}

Rad primljen: 23. 11. 2015.

Rad prihvaćen: 31. 122015.

Rad je dostupan na sajtu: www.idk.org.rs/casopis 